Sigma Teknika, Vol.2, No.2 : 192-201

November 2019

E-ISSN 2599-0616

P ISSN 2614-5979

\title{
KRAN AIR OTOMATIS PADA TEMPAT BERWUDHU MENGGUNAKAN SENSOR ULTRASONIK BERBASIS ARDUINO UNO
}

\author{
Romi Shaputra ${ }^{1}$, Pamor Gunoto ${ }^{2}$, Muhammad Irsyam ${ }^{3}$, \\ ${ }^{1,2,3)}$ Program Studi Teknik Elektro, Fakultas Teknik, Universitas Riau Kepuluan Batam \\ Email : Saputraromi12@gmail.com
}

\begin{abstract}
Abstrak
Perancangan kran air otomatis pada tempat berwudhu menggunakan sensor ultrasonik berbasis arduino uno merupakan sebuah perancangan kran otomatis di tempat wudhu yang digunakan untuk menghemat pemakaian air dengan mengontrol pemakaian air ketika sedang berwudhu. Alat ini dikontrol dengan menggunakan arduino uno sebagai pengendali utama, kran air otomatis ini menggunakan sensor ultrasonik sebagai pendeteksi keberadaan object atau anggota tubuh manusia yang sedang berwudhu. Prinsip kerja alat ini adalah ketika arduino uno dihubungkan dengan power supply, maka arduino uno akan menginisialisasi semua komponen yang ada pada alat ini. Kemudian ketika sensor ultrasonik mendeteksi keberadaan object dengan jarak $\leq 30 \mathrm{~cm}$, maka relay akan aktif dan menghidupkan solenoid valve. Dan ketika sensor ultrasonik tidak mendeteksi keberadaan object dengan jarak $\leq 30 \mathrm{~cm}$ maka relay mati dan solenoid valve juga mati. Jarak deteksi sensor ultrasonik pada alat ini adalah $\leq 30 \mathrm{~cm}$.
\end{abstract}

Kata kunci $\quad$ : Arduino Uno, Sensor Ultrasonik, LCD, Relay, Solenoid Valve.

\begin{abstract}
Designing automatic water valve on the ablution place using ultrasonic sensor based arduino uno is a designing automatic valve on the ablution place for saving the water usage by controlled water usage while performing ablution. This device is controlled by using arduino uno as the main controller and ultrasonic sensor as detector of object or the parts of human body who performing ablution. Work principle of this device is when arduino uno is connected with power supply, so arduino uno will initialize all of components on this device. Then when ultrasonic sensor detects object's existence in distance $\leq 30 \mathrm{~cm}$, so relay will active and switch on the solenoid valve. And when ultrasonic sensor does not detect object's existence in distance $\leq 30 \mathrm{~cm}$, so relay will unactive and solenoid valve will switch off. The detection distance of the ultrasonic sensor on this device is $\leq 30$ $\mathrm{cm}$.
\end{abstract}

Key words $\quad$ : Arduino Uno, Ultrasonic Sensor, LCD, Relay, Solenoid Valve. 


\section{PENDAHULUAN}

Sebagai umat muslim kita diwajibkan untuk melaksanakan ibadah sholat 5 waktu sehari semalam, yang mana salah satu syarat sah sholat adalah berwudhu. Tetapi pada saat berwudhu, sering kita dapati banyaknya terjadi pemborosan dalam pemakaian air. Pemborosan ini terjadi karena pada tempat tersebut, masih menggunakan kran air manual yang mana kran air ini akan terus mengeluarkan air kalau kranya tidak ditutup. Tentu akan susah untuk menutup kran air ketika hendak membasuh muka, rambut, telinga dan lain sebagainya ketika sedang berwudhu. Dan kalau tidak ditutup, maka pemborosan air akan terjadi. Untuk itu perlulah sekiranya diterapkan kran air otomatis di tempat-tempat wudhu supaya lebih efisien pada saat berwudhu dan pemakain airpun bisa terkontrol. Dengan dilatar belakangi oleh masalah tersebut maka penulis tertarik untuk merancang sebuah alat yaitu "Kran Air Otomatis Pada Tempat Berwudhu Menggunakan Sensor Ultrasonik Berbasis Arduino Uno".

Penelitian tentang sensor ultrasonik telah dilakukan oleh para peneliti sebelumnya diantaranya oleh Ilfan Arifin pada tahun 2015, dalam penelitiannya yang berjudul automatic water level control berbasis mikrocontroller dengan sensor ultrasonik. Hasil yang diperoleh adalah berupa alat yang dapat menghidupkan pompa air secara otomatis ketika tandon air kosong dan mati ketika tandon air sudah penuh. Komponen-komponen yang digunakan dalam penelitian ini adalah sensor ultrasonik HC-SR04, mikrokontroler Atmega 328, relay, LCD, dan pompa air. [5]

Pada tahun 2016 Alfian Lantoni Herananda dalam penelitiannya yang berjudul prototype alat bantu parkir mobil berbasis sensor ultrasonik ping dan mikrokontroler arduino uno. Hasil yang diperoleh adalah berupa alat yang dapat membantu pengemudi pada saat memarkir kendaraanya. Komponenkomponen yang digunakan adalah arduino uno, sensor ultrasonik HC-SR04 dan car parking. [8]

Pada tahun 2017 Febry Hario Wibowo dalam penelitiannya yang berjudul prototype smart bathroom berbasis arduino uno. Hasil yang diperoleh adalah sebuah alat bantu di kamar mandi untuk menghidup dan mematikan air dari shower secara otomatis. Komponenkomponen yang digunakan antara lain adalah arduino uno, sensor ultrasonik HC-SR04, sensor LDR dan selenoid valve. [11]

Pada tahun 2013 Sutris Astaril dalam penelitiannya yang berjudul kran air wudhu otomatis berbasis arduino ATmega 328. Hasil yang diperoleh adalah sebuah kran wudhu yang bisa mengalirkan air secara otomatis. Adapun komponen-komponen yang digunakan pada penelitian ini adalah mikrokontroler Atmega 328 , sensor PIR, selenoid valve, pompa air dan relay. [6]

Berdasarkan penelitian tersebut, sensor ultrasonik lebih bagus digunakan untuk mendeteksi suatu benda. Karena kalau menggunakan sensor PIR, bisa jadi bukan hanya tangan orang yang sedang berwudhu yang terdeteksi, tapi sensor juga bisa mendeteksi orang yang sedang berjalan di sekitar kran. Sehingga air akan tetap mengalir. Oleh karena itu, penulis mencoba untuk melakukan penelitian tentang perancangankran air otomatis pada tempat berwudhu menggunakan sensor ultrasonik berbasis arduino uno. Dengan adanya penelitian ini diharapkan agar umat islam bisa lebih efisien dalam berwudhu.

\section{LANDASAN TEORI}

\section{A. Power Supply}

Power supply adalah suatu perangkat keras elektronika yang mempunyai fungsi sebagai supplier arus listrik dengan terlebih dahulu merubah tegangannya dari AC menjadi DC. Jadi arus listrik PLN yang bersifat Alternating Current (AC) masuk ke power supply kemudian diubah menjadi Direct Current (DC) baru kemudian dialirkan ke komponen lain yang membutuhkannya. [9]

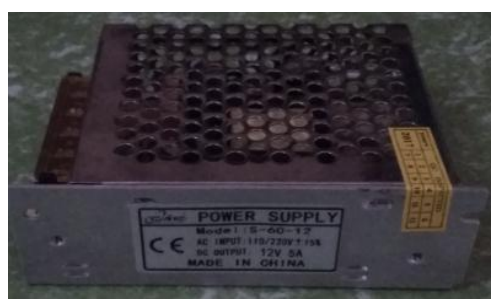

Gambar 2.1 Power supply [9] 
Power Supply pada dasarnya memiliki 4 bagian utama agar dapat menghasilkan arus DC yang stabil. Keempat bagian utama tersebut diantaranya adalah:

\section{Transformator}

Transformator yang digunakan untuk power supply adalah transformator jenis stepdown yang berfungsi untuk menurunkan tegangan listrik sesuai dengan kebutuhan komponen elektronika yang terdapat pada rangkaiannya. Transformator bekerja berdasarkan prinsip induksi elektromagnetik yang terdiri dari 2 bagian utama yang berbentuk lilitan yaitu lilitan primer dan lilitan sekunder. Lilitan primer merupakan input dari transformator sedangkan outputnya adalah lilitan sekunder.

\section{Rectifier}

Rectifier atau penyearah gelombang adalah rangkaian elektronika dalam power supply yang berfungsi untuk mengubah gelombang AC menjadi gelombang DC setelah tegangannya diturunkan oleh transformator step down.

\section{Filter}

Dalam rangkaian power supply, filter digunakan untuk meratakan sinyal arus yang keluar dari rectifier. Filter ini biasanya terdiri dari komponen kapasitor.

\section{Voltage regulator}

Untuk menghasilkan tegangan dan arus DC yang tetap dan stabil, diperlukan voltage regulator yang berfungsi untuk mengatur tegangan sehingga tegangan output tidak dipengaruhi oleh suhu, arus beban dan juga tegangan input yang berasal output filter. Voltage regulator pada umumnya terdiri dari dioda zener, transistor atau IC (integrated circuit). [9]

\section{B. Arduino}

Menurut Syahwil (2017) arduino adalah pengendali mikro yang dapat diprogram dan dibuat dalam board mikrokontroler yang siap pakai dan di dalamnya terdapat komponen utama yaitu sebuah chip mikrokontroler jenis AVR. Arduino terdiri dari dua bagian utama, yaitu perangkat lunak (software) dan perangkat keras (hardware). Perangkat lunaknya berupa sebuah aplikasi yang disebut dengan Arduino IDE. [10]
IDE arduino adalah software yang digunakan untuk membuat, menulis, memodifikasi, dan menggunggah kode program arduino. Sedangkan perangkat kerasnya berupa sebuah board. Ada banyak variasi dari hardware arduino, diantaranya adalah Arduino Uno R3, Arduino Mega, Arduino nano, arduino bluetooth, arduino lilypad, dan lain sebagainya. [10]

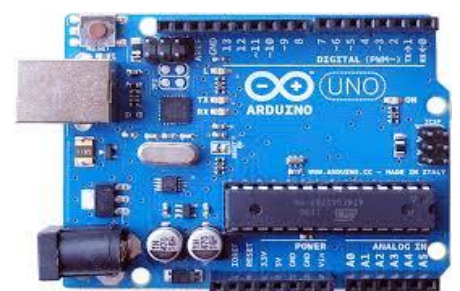

Gambar 2.2 Arduino uno [1]

\section{Sensor ultrasonik HC-SR04}

Sensor ultrasonik HC-SR04 adalah sensor yang bekerja berdasarkan prinsip pantulan gelombang suara dan digunakan untuk mendeteksi keberadaan suatu object tertentu di depannya, frekuensi kerjanya di atas gelombang suara dari $40 \mathrm{KHz}$ hingga 400 KHz. Sensor ultrasonik HC-SR04 terdiri dari dua unit, yaitu unit pemancar dan unit penerima. Struktur unit pemancar dan penerima adalah sebuah kristal piezoelectric dihubungkan dengan mekanik jangkar dan dihubungkan dengan diafragma penggetar. Tegangan bolak-balik yang memiliki frekuensi kerja $40 \mathrm{KHz}-400 \mathrm{KHz}$ diberikan pada plat logam. Struktur atom dari kristal piezoelectric akan berkontraksi (mengikat), mengembang atau menyusut terhadap polaritas tegangan yang diberikan dan ini disebut dengan efek piezoelectric. Kontraksi yang terjadi diteruskan ke diafragma penggetar sehingga terjadi gelombang ultrasonik yang dipancarkan ke udara (tempat sekitarnya). Pantulan gelombang ultrasonik akan terjadi bila ada object tertentu dan pantulan gelombang ultrasonik akan diterima kembali oleh unit sensor penerima. Selanjutnya unit sensor penerima akan menyebabkan diafragma penggetar akan bergetar dan efek piezoelectric menghasilkan sebuah tegangan bolak-balik dengan frekuensi yang sama. [5] 


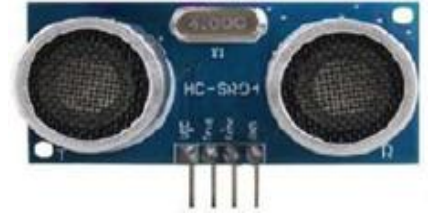

Gambar 2.3 Sensor ultrasonik HC-SR04 [5]

Pantulan gelombang ultrasonik dapat dimanfaatkan untuk mengukur jarak antara sensor dan benda yang secara ideal dapat dihitung dengan rumus sebagai berikut :

$\mathrm{S}=\frac{\mathrm{v} \cdot \mathrm{t}}{2}$

$\mathrm{t}=\frac{2 . \mathrm{s}}{\mathrm{v}}$

Dimana :

$\mathrm{s}=$ jarak object dengan sensor $(\mathrm{m})$

$\mathrm{t}=$ waktu tempuh atau lebar pulsa (detik)

$\mathrm{v}=$ cepat rambat suara di udara yaitu 340 $\mathrm{m} / \operatorname{detik}$ (1 cm setiap 29,034 $\mu \mathrm{S}$ )

Untuk menentukan jarak pada mikrokontroler, mikrokontroler cukup mengukur lebar pulsa atau waktu tempuh dan mengkonversinya dalam bentuk jarak dengan persamaan sebagai berikut:

Jarak LCD $=\frac{\text { lebar pulsa }}{29,034}$

Dimana :

Jarak : jarak object dengan sensor (m)

Lebar pulsa : waktu tempuh (detik)

29,034: $1 \mathrm{~cm}$ setiap 29,034 $\mu \mathrm{S}$

\section{Relay}

Relay adalah sakelar (switch) yang dioperasikan secara listrik dan merupakan komponen Electromechanical yang terdiri dari 2 bagian utama yakni Electromagnet (coil) dan mekanikal (seperangkat kontak sakelar atau Switch). Relay menggunakan prinsip electromagnetik untuk menggerakkan kontak saklar sehingga dengan arus listrik yang kecil (low power) dapat menghantarkan listrik yang bertegangan lebih tinggi. Relay yang menggunakan elektromagnet $5 \mathrm{~V}$ dan $50 \mathrm{~mA}$ mampu menggerakan armature relay (yang berfungsi sebagai saklarnya) untuk menghantarkan listrik 220V 2A. [3]

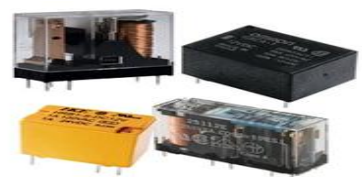

Gambar 2.4 Relay [3]

\section{E. Selenoid Valve}

Solenoid valve atau katup listrik merupakan katup yang dikendalikan dengan arus listrik baik AC maupun DC melalui kumparan atau selenoida. Solenoid valve sering digunakan untuk mengontrol sistem fluida. Seperti pada sistem pneumatic, sistem hidrolic ataupun pada sistem kontrol mesin yang membutuhkan elemen kontrol otomatis. Contohnya pada sistem pneumatic, solenoid valve digunakan untuk mengontrol saluran udara yang bertekanan menuju aktuator pneumatic (cylinder). Pada sebuah tandon air solenoid valve digunakan sebagai pengatur pengisian air, sehingga tandon tersebut tidak sampai kosong. Pada perancangan ini, selenoid valve digunakan sebagai alat umtuk membuka dan menutup kran air. Yaitu ketika sensor ultrasonik mendeteksi adanya object, maka selenoid valve akan terbuka. Dan jika sensor ultrasonik tidak mendeteksi object, maka selenoid valve akan tertutup. [4]

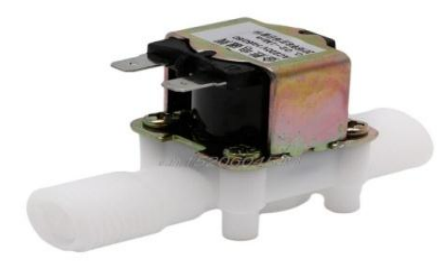

Gambar 2.5 Selenoid valve [4]

\section{F. LCD (Liquid Crystal Display)}

Menurut Syahwil (2017) Liquid Crystal Display atau yang sering disingkat dengan LCD adalah suatu jenis media tampilan yang menggunakan kristal cair sebagai penampil utama. Sebagaimana sering kita lihat, LCD sudah digunakan di berbagai perangkat elektronik misalnya kalkulator, jam digital, televisi maupun pada layar komputer atau 
laptop. Karakter LCD memiliki beberapa ukuran jumlah dan baris kolomnya, antara lain $8 \times 2,16 \times 2,20 \times 2,20 \times 4$ dan sebagainya. Pada tugas akhir ini penulis akan menggunakan LCD 16x2. [10]

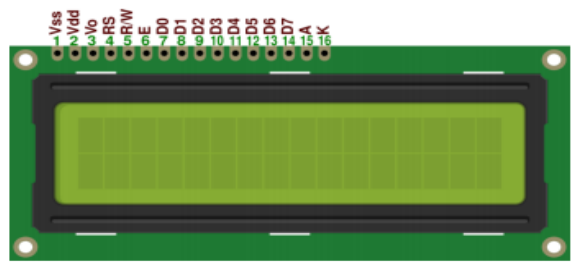

Gambar 2.6 LCD 16x2 [10]

\section{G. Persamaan Untuk Mencari Persentase Kesalahan dan Rata-Rata Kesalahan.}

1. Persamaan untuk mencari persentase kesalahan.

Persentase kesalahan $=\frac{\text { aktual }- \text { terbaca }}{\text { aktual }} \times 100 \%$ 4

2. Persamaan untuk mencari nilai rata-rata kesalahan.

Rata-rata $=\frac{\mathrm{n}}{\mathrm{N}}$

\section{METODOLOGI PENELITIAN}

A. Perancangan sistem

Untuk mempermudah pemahaman tentang perancangan kran otomatis pada tempat berwudhu dengan menggunakan sensor ultrasonik berbasis arduino uno ini, maka dibuatlah alir penelitiannya. Adapun alir penelitian dari penelitian ini adalah:

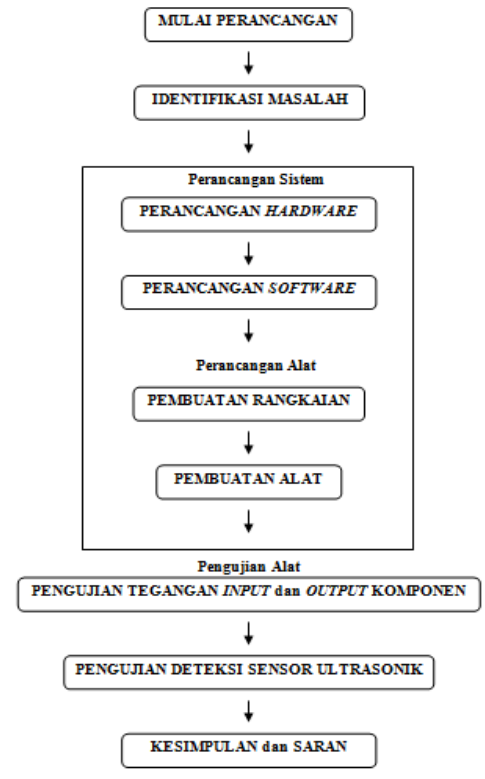

Gambar 3.1 Diagram alir penelitian

\section{B. Blok diagram alat}

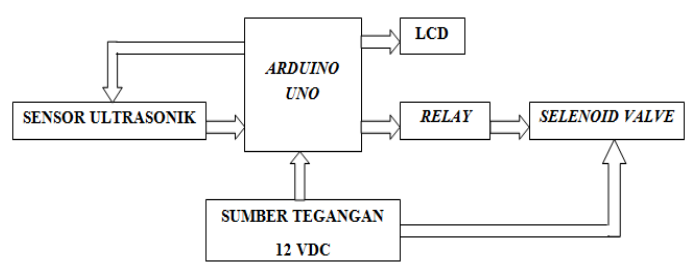

Gambar 3.2 Blok diagram alat

\section{Flowchart alat}

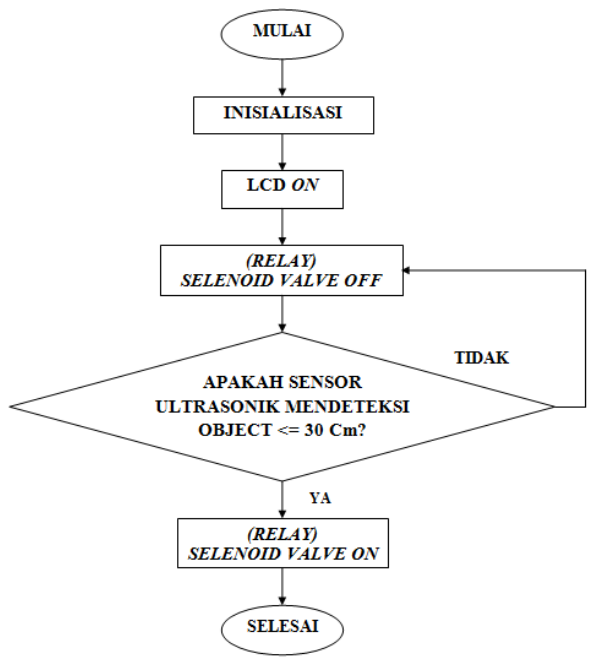

Gambar 3.3 Flowchart alat 


\section{Wiring diagram}

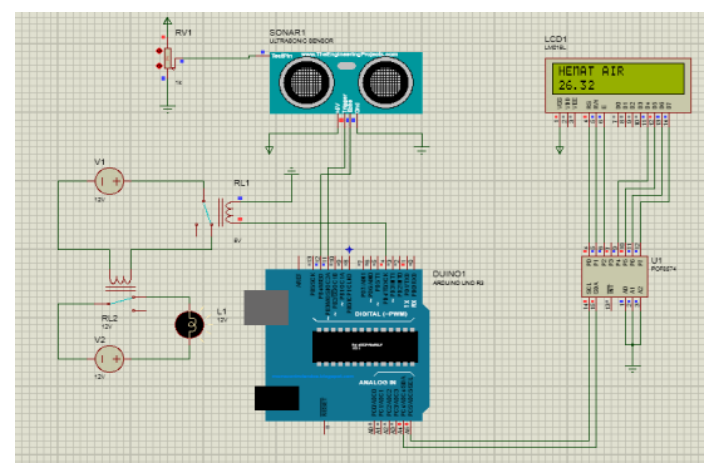

Gambar 3.4 Wiring diagram alat

\section{E. Gambar alat keseluruhan}

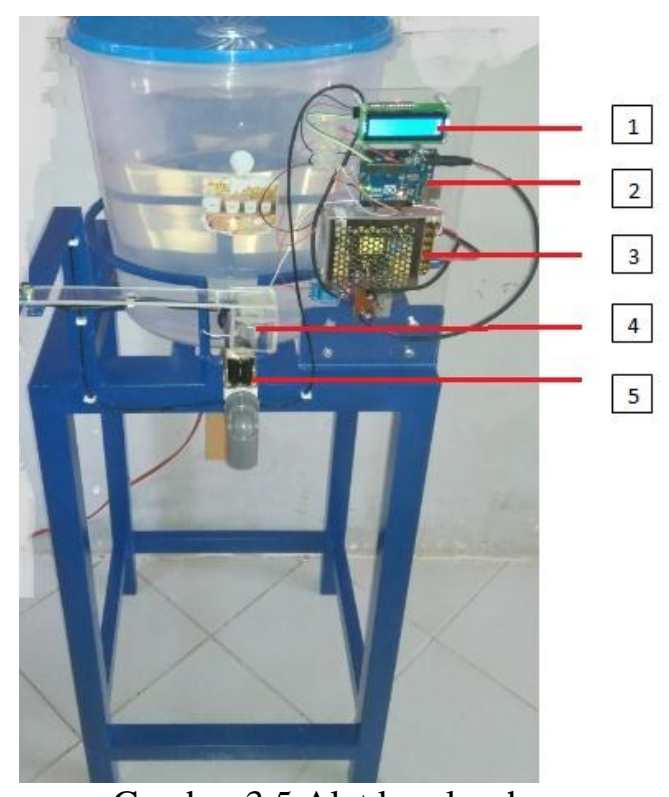

Keterangan :

1. LCD.

2. Arduino uno R3.

3. Power supply.

4. Sensor ultrasonik.

5. Selenoid valve.

\section{HASIL DAN PEMBAHASAN}

A. Pengujian Tegangan Input dan Output

\section{Komponen}

Pengujian tegangan input dan output komponen dilakukan dengan cara mengukur tegangan dari setiap komponen dengan menggunakan multimeter. Adapun hasil dari pengukuran tegangan tersebut ditunjukan pada tabel 4.1 di bawah ini.
Tabel 4.1 Hasil pengujian tegangan input dan output komponen

\begin{tabular}{|c|c|c|c|}
\hline $\mathrm{N}_{0}$ & Nama Komponen & $\begin{array}{l}\text { Tegangan Input } \\
\text { (V) }\end{array}$ & $\begin{array}{l}\text { Tegangan Output } \\
\text { (V) }\end{array}$ \\
\hline 1 & Power Supply & $220 \mathrm{VAC}$ & $12 \mathrm{VDC}$ \\
\hline 2 & Arduino Uno & $12 \mathrm{VDC}$ & $5 \mathrm{VDC}$ \\
\hline 3 & Sensor Ultrasonik & $5 \mathrm{VDC}$ & - \\
\hline 4 & LCD & $5 \mathrm{VDC}$ & - \\
\hline 5 & Solenoid Valve & $12 \mathrm{VDC}$ & - \\
\hline 6 & Relay & $5 \mathrm{VDC}$ & $12 \mathrm{VDC}$ \\
\hline
\end{tabular}

\section{B. Pengujian Deteksi Sensor Ultrasonik}

Pengujian deteksi sensor ultrasonik dilakukan dengan cara mengukur jarak jangkauan sensor ultrasonik dengan penggaris (jarak sebenarnya) dan melihat jarak yang ditampilkan pada display LCD. Untuk mencari persentase kesalahan dari jarak tersebut, maka digunakan persamaan 4 yaitu:

Persentase kesalahan $=\frac{\text { aktual }- \text { terbaca }}{\text { aktual }} \times 100 \%$

Adapun hasil dari pengujian deteksi sensor dan persentase kesalahan ditunjukan pada tabel 4.2 di bawah ini.

Tabel 4.2 Pengujian deteksi sensor ultrasonik 
Sigma Teknika, Vol.2, No.2 : 192-201

November 2019

E-ISSN 2599-0616

P ISSN 2614-5979

\begin{tabular}{|c|l|c|c|c|}
\hline No & Percobaan & $\begin{array}{c}\text { Jarak Sebenamya } \\
(\mathrm{Cm})\end{array}$ & $\begin{array}{c}\text { Jarak Pada } \\
\text { LCD }(\mathrm{Cm})\end{array}$ & $\begin{array}{c}\text { Persentasi } \\
\text { Kesalahan }(\%)\end{array}$ \\
\hline 1 & Percobaan 1 & $2 \mathrm{~cm}$ & 2,271 & $13,55 \%$ \\
\hline 2 & Percobaan 2 & $5 \mathrm{~cm}$ & 4,549 & $9,02 \%$ \\
\hline 3 & Percobaan 3 & $7 \mathrm{~cm}$ & 6,399 & $8,59 \%$ \\
\hline 4 & Percobaan 4 & $10 \mathrm{~cm}$ & 9,525 & $4,75 \%$ \\
\hline 5 & Percobaan 5 & $12 \mathrm{~cm}$ & 11,758 & $2,01 \%$ \\
\hline 6 & Percobaan 6 & $14 \mathrm{~cm}$ & 13,668 & $2,37 \%$ \\
\hline 7 & Percobaan 7 & $15 \mathrm{~cm}$ & 14,798 & $1,34 \%$ \\
\hline 8 & Percobaan 8 & $16 \mathrm{~cm}$ & 15,748 & $1,57 \%$ \\
\hline 9 & Percobaan 9 & $17 \mathrm{~cm}$ & 16,748 & $1,48 \%$ \\
\hline 10 & Percobaan 10 & $18 \mathrm{~cm}$ & 17,638 & $2,01 \%$ \\
\hline 11 & Percobaan 11 & $20 \mathrm{~cm}$ & 19,578 & $2,11 \%$ \\
\hline 12 & Percobaan 12 & $21 \mathrm{~cm}$ & 20,888 & $0,53 \%$ \\
\hline 13 & Percobaan 13 & $22 \mathrm{~cm}$ & 21,568 & $1,96 \%$ \\
\hline 14 & Percobaan 14 & $23 \mathrm{~cm}$ & 22,568 & $1,87 \%$ \\
\hline 15 & Percobaan 15 & $24 \mathrm{~cm}$ & 23,478 & $2,17 \%$ \\
\hline 16 & Percobaan 16 & $25 \mathrm{~cm}$ & 24,798 & $0,80 \%$ \\
\hline 17 & Percobaan 17 & $26 \mathrm{~cm}$ & 25,408 & $2,27 \%$ \\
\hline 18 & Percobaan 18 & $27 \mathrm{~cm}$ & 26,738 & $0,97 \%$ \\
\hline 19 & Percobaan 19 & $28 \mathrm{~cm}$ & 27,658 & $1,22 \%$ \\
\hline 20 & Percobaan 20 & $30 \mathrm{~cm}$ & 29,308 & $2,30 \%$ \\
\hline \multicolumn{4}{|r|}{ Jumlah persentase kesalahan } & $62,89 \%$ \\
\hline
\end{tabular}

Selanjutnya untuk mendapatkan nilai rata-rata kesalahan, maka dapat dicari dengan menggunakan persamaan 5 yaitu:

Rata-rata kesalahan $=\frac{\mathrm{n}}{\mathrm{N}}=\frac{62,89 \%}{20}=3,14 \%$

Jadi rata-rata kesalahan dari jarak sebenarnya dengan jarak tampilan pada LCD adalah $3,14 \%$.

Berikut ini adalah beberapa contoh pengukuran jarak sensor ultrasonik dan tampilan jaraknya pada LCD.

\section{Jarak $10 \mathrm{~cm}$}

Pada jarak $10 \mathrm{~cm}$, jarak yang ditampilkan pada display LCD adalah 9,525 $\mathrm{cm}$. Dengan menggunakan persamaan 4, maka persentase kesalahan dari pengukuran pada jarak $10 \mathrm{~cm}$ adalah:

$\frac{10-9,525}{10} \times 100 \%=0,0475 \times 100 \%=4,75 \%$

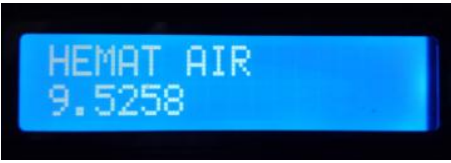

Gambar 4.1 Tampilan jarak pada LCD

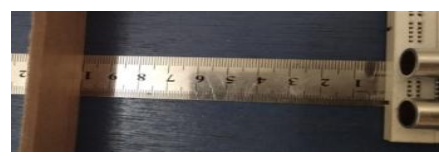

Gambar 4.2 Jarak sebenarnya dengan diukur penggaris

Tabel 4.3 Pengukuran pada jarak $10 \mathrm{~cm}$

\begin{tabular}{|c|c|c|}
\hline $\begin{array}{c}\text { Jarak } \\
\text { sebenarnya } \\
(\mathrm{Cm})\end{array}$ & $\begin{array}{c}\text { Jarak pada } \\
\text { LCD }(\mathrm{Cm})\end{array}$ & $\begin{array}{c}\text { Persentase } \\
\text { kesalahan }(\%)\end{array}$ \\
\hline 10 & 9,525 & 4,75 \\
\hline
\end{tabular}

Untuk menentukan jarak pada tampilan LCD, digunakan persamaan 3 yaitu:

Jarak LCD $=\frac{\text { lebar pulsa }}{29,034}: 2$

Namun sebelum menentukan nilai jarak tersebut, terlebih dahulu kita harus menentukan nilai dari lebar pulsa. Adapun untuk menentukan lebar pulsa, digunakan persamaan 2 yaitu:

$\mathrm{t}=\frac{2 . \mathrm{s}}{\mathrm{v}}$

$\mathrm{t}=\frac{2 \times 9,525 \mathrm{~cm}}{340 \mathrm{~m} / \mathrm{s}}=\frac{2 \times 0,095 \mathrm{~m}}{340 \mathrm{~m} / \mathrm{s}}=\frac{0,190 \mathrm{~s}}{340}$

$=0,000558823 \mathrm{~s}=558,823 \mu \mathrm{S}$

Setelah nilai lebar pulsa diperoleh yaitu $558,823 \mu S$, selanjutnya mencari nilai jarak pada tampilan LCD berdasarkan persamaan 3 yang penulis sebutkan di atas yaitu:

jarak LCD $=\frac{\text { lebar pulsa }}{29,034 \mu \mathrm{S}}: 2=\frac{558,823 \mu \mathrm{S}}{29,034 \mu \mathrm{S}}: 2$

$=\frac{19,247}{2}=9,623 \mathrm{~cm}$

\section{Jarak $15 \mathrm{Cm}$}

Pada jarak $15 \mathrm{~cm}$, jarak yang ditampilkan pada display LCD adalah 14,798 $\mathrm{cm}$. Dengan menggunakan persamaan 4, maka persentase kesalahan dari pengukuran pada jarak $15 \mathrm{~cm}$ adalah:

$$
\frac{15-14,798}{15} \times 100 \%=0,0134 \times 100 \%=1,34 \%
$$

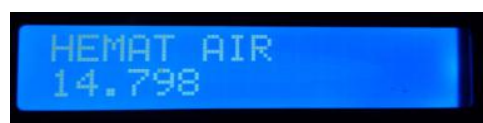

Gambar 4.3 Tampilan jarak pada LCD 


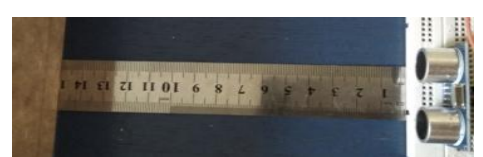

Gambar 4.4 Jarak sebenarnya dengan diukur penggaris

Tabel 4.4 Pengukuran pada jarak $15 \mathrm{~cm}$

\begin{tabular}{|c|c|c|}
\hline $\begin{array}{c}\text { Jarak } \\
\text { sebenarnya } \\
(\mathrm{Cm})\end{array}$ & $\begin{array}{c}\text { Jarak pada } \\
\text { LCD }(\mathrm{Cm})\end{array}$ & $\begin{array}{c}\text { Persentase } \\
\text { kesalahan }(\%)\end{array}$ \\
\hline 15 & 14,798 & 1,34 \\
\hline
\end{tabular}

Untuk menentukan jarak pada tampilan LCD, digunakan persamaan 3 yaitu:

Jarak LCD $=\frac{\text { lebar pulsa }}{29,034}: 2$

Namun sebelum menentukan nilai jarak tersebut, terlebih dahulu kita harus menentukan nilai dari lebar pulsa. Adapun untuk menentukan lebar pulsa, digunakan persamaan 2 yaitu:

$\mathrm{t}=\frac{2 . \mathrm{s}}{\mathrm{v}}$

$\mathrm{t}=\frac{2 \mathrm{x} 14,798 \mathrm{~cm}}{340 \mathrm{~m} / \mathrm{s}}=\frac{2 \times 0,147 \mathrm{~m}}{340 \mathrm{~m} / \mathrm{s}}=\frac{0,294 \mathrm{~s}}{340}$

$=0,000864705 \mathrm{~s}=864,705 \mu \mathrm{S}$

Setelah nilai lebar pulsa diperoleh yaitu $864,705 \mu S$, selanjutnya mencari nilai jarak pada tampilan LCD berdasarkan persamaan 3 yang penulis sebutkan di atas yaitu:

jarak LCD $=\frac{\text { lebar pulsa }}{29,034 \mu \mathrm{S}}: 2=\frac{864,705 \mu \mathrm{S}}{29,034 \mu \mathrm{S}}: 2$ $=\frac{29,782}{2}=14,891 \mathrm{~cm}$

\section{Jarak $20 \mathrm{Cm}$}

Pada jarak $20 \mathrm{~cm}$, jarak yang ditampilkan pada display LCD adalah 19,578 $\mathrm{cm}$. Dengan menggunakan persamaan 4, maka persentase kesalahan dari pengukuran pada jarak $20 \mathrm{~cm}$ adalah:

$$
\frac{20-19,578}{20} \times 100 \%=0,0211 \times 100 \%=2,11 \%
$$

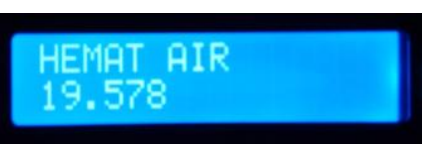

Gambar 4.5 Tampilan jarak pada LCD

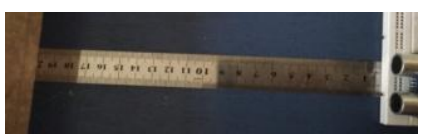

Gambar 4.6 Jarak sebenarnya diukur dengan penggaris

Tabel 4.5 Pengukuran pada jarak $20 \mathrm{~cm}$

\begin{tabular}{|c|c|c|}
\hline $\begin{array}{c}\text { Jarak } \\
\text { sebenarnya } \\
(\mathrm{Cm})\end{array}$ & $\begin{array}{c}\text { Jarak pada } \\
\text { LCD }(\mathrm{Cm})\end{array}$ & $\begin{array}{c}\text { Persentase } \\
\text { kesalahan }(\%)\end{array}$ \\
\hline 20 & 19,578 & 2,11 \\
\hline
\end{tabular}

Untuk menentukan jarak pada tampilan LCD, digunakan persamaan 3 yang terdapat pada halaman 19 yaitu:

Jarak LCD $=\frac{\text { lebar pulsa }}{29,034}: 2$

Namun sebelum menentukan nilai jarak tersebut, terlebih dahulu kita harus menentukan nilai dari lebar pulsa. Adapun untuk menentukan lebar pulsa, digunakan persamaan 2 yaitu:

$\mathrm{t}=\frac{2 . \mathrm{s}}{\mathrm{v}}$

$\mathrm{t}=\frac{2 \mathrm{x} 19,578 \mathrm{~cm}}{340 \mathrm{~m} / \mathrm{s}}=\frac{2 \times 0,195 \mathrm{~m}}{340 \mathrm{~m} / \mathrm{s}}=\frac{0,390 \mathrm{~s}}{340}$

$=0,00114705 \mathrm{~s}=1.147,058 \mu \mathrm{S}$

Setelah nilai lebar pulsa diperoleh yaitu $1.147,058 \mu S$, selanjutnya mencari nilai jarak pada tampilan LCD berdasarkan persamaan 3 yang penulis sebutkan di atas yaitu:

jarak LCD $=\frac{\text { lebar pulsa }}{29,034 \mu \mathrm{S}}: 2=\frac{1.147,058 \mu \mathrm{S}}{29,034 \mu \mathrm{S}}: 2$ $=\frac{39,507}{2}=19,753 \mathrm{~cm}$

\section{Jarak $25 \mathrm{Cm}$}

Pada jarak $25 \mathrm{~cm}$, jarak yang ditampilkan pada display LCD adalah 24,798 $\mathrm{cm}$. Dengan menggunakan persamaan 4, maka persentase kesalahan dari pengukuran pada jarak $25 \mathrm{~cm}$ adalah: 
$\frac{25-24,798}{25} \times 100 \%=0,0080 \times 100 \%=0,80 \%$

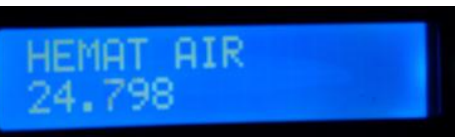

Gambar 4.7 Tampilan jarak pada LCD

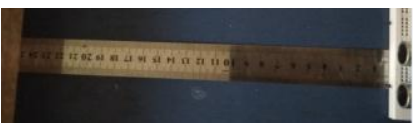

Gambar 4.8 Jarak sebenarnya diukur dengan penggaris

Tabel 4.6 Pengukuran pada jarak $25 \mathrm{~cm}$

\begin{tabular}{|c|c|c|}
\hline $\begin{array}{c}\text { Jarak } \\
\text { sebenarnya } \\
(\mathrm{Cm})\end{array}$ & $\begin{array}{c}\text { Jarak pada } \\
\text { LCD }(\mathrm{Cm})\end{array}$ & $\begin{array}{c}\text { Persentase } \\
\text { kesalahan }(\%)\end{array}$ \\
\hline 25 & 24,798 & 0,80 \\
\hline
\end{tabular}

Untuk menentukan jarak pada tampilan LCD, digunakan persamaan 3 yaitu:

Jarak LCD $=\frac{\text { lebar pulsa }}{29,034}: 2$

Namun sebelum menentukan nilai jarak tersebut, terlebih dahulu kita harus menentukan nilai dari lebar pulsa. Adapun untuk menentukan lebar pulsa, digunakan persamaan 2 yaitu:

$\mathrm{t}=\frac{2 . \mathrm{s}}{\mathrm{V}}$

$\mathrm{t}=\frac{2 \times 24,798 \mathrm{~cm}}{340 \mathrm{~m} / \mathrm{s}}=\frac{2 \times 0,247 \mathrm{~m}}{340 \mathrm{~m} / \mathrm{s}}=\frac{0,494 \mathrm{~s}}{340}$

$=0,001452941 \mathrm{~s}=1.452,941 \mu \mathrm{S}$

Setelah nilai lebar pulsa diperoleh yaitu $1.452,941 \mu S$, selanjutnya mencari nilai jarak pada tampilan LCD berdasarkan persamaan 3 yang penulis sebutkan di atas yaitu:

jarak LCD $=\frac{\text { lebar pulsa }}{29,034 \mu \mathrm{S}}: 2=\frac{1.452,941 \mu \mathrm{S}}{29,034 \mu \mathrm{S}}: 2$ $=\frac{50,042}{2}=25,021 \mathrm{~cm}$

5. Jarak $30 \mathrm{Cm}$

Pada jarak $30 \mathrm{~cm}$, jarak yang ditampilkan pada display LCD adalah 29,308 $\mathrm{cm}$. Dengan menggunakan persamaan 4, maka persentase kesalahan dari pengukuran pada jarak $30 \mathrm{~cm}$ adalah:

\section{$\frac{30-29,308}{30} \times 100 \%=0,0230 \times 100 \%=2,30 \%$ \\ HEMAT AIR 29.368}

Gambar 4.9 Tampilan jarak pada LCD

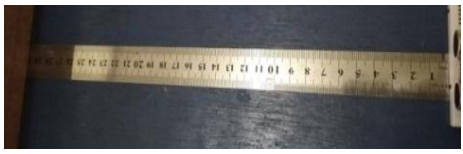

Gambar 4.10 Jarak sebenarnya diukur dengan penggaris

Tabel 4.7 Pengukuran pada jarak $30 \mathrm{~cm}$

\begin{tabular}{|c|c|c|}
\hline $\begin{array}{c}\text { Jarak } \\
\text { sebenarnya } \\
(\mathrm{Cm})\end{array}$ & $\begin{array}{c}\text { Jarak pada } \\
\text { LCD }(\mathrm{Cm})\end{array}$ & $\begin{array}{c}\text { Persentase } \\
\text { kesalahan }(\%)\end{array}$ \\
\hline 30 & 29,308 & 2,30 \\
\hline \multicolumn{2}{|c|}{ Untuk menentukan jarak pada }
\end{tabular}

tampilan LCD, digunakan persamaan 3 yaitu:

Jarak LCD $=\frac{\text { lebar pulsa }}{29,034}: 2$

Sebelum menentukan nilai jarak tersebut, terlebih dahulu kita harus menentukan nilai dari lebar pulsa. Adapun untuk menentukan lebar pulsa, digunakan persamaan 2 yaitu:

$\mathrm{t}=\frac{2 . \mathrm{s}}{\mathrm{V}}$

$\mathrm{t}=\frac{2 \mathrm{x} 29,308 \mathrm{~cm}}{340 \mathrm{~m} / \mathrm{s}}=\frac{2 \times 0,293 \mathrm{~m}}{340 \mathrm{~m} / \mathrm{s}}=\frac{0,586 \mathrm{~s}}{340}$

$=0,00172352 \mathrm{~s}=1.723,529 \mu \mathrm{S}$

Setelah nilai lebar pulsa diperoleh yaitu $1.723,529 \mu S$, selanjutnya mencari nilai jarak pada tampilan LCD berdasarkan persamaan 3 yang penulis sebutkan di atas yaitu:

jarak LCD $=\frac{\text { lebar pulsa }}{29,034 \mu \mathrm{S}}: 2=\frac{1.723,529 \mu \mathrm{S}}{29,034 \mu \mathrm{S}}: 2$

$=\frac{59,362}{2}=29,681 \mathrm{~cm}$ 
Sigma Teknika, Vol.2, No.2 : 192-201

November 2019

E-ISSN 2599-0616

P ISSN 2614-5979

\section{KESIMPULAN DAN SARAN}

A. Kesimpulan

Setelah melakukan perancangan dan pengujian serta pengambilan data pada perancangan kran air otomatis pada tempat berwudhu menggunakan sensor ultrasonik berbasis arduino uno, maka penulis menarik kesimpulan bahwa kran air otomatis yang penulis buat ini dikontrol oleh arduino uno dengan sensor ultrasonik sebagai pendeteksi keberadaan object atau anggota tubuh manusia yang sedang berwudhu. Jarak deteksi sensor ultrasonik ini adalah $\leq 30 \mathrm{~cm}$. Artinya jika sensor mendeteksi object di bawah $30 \mathrm{~cm}$ maka selenoid valve akan hidup, dan jika sensor mendeteksi object di atas $30 \mathrm{~cm}$, maka selenoid valve akan mati. Dengan rata-rata kesalahan error adalah 3,14\%

\section{B. Saran}

Dari hasil perancangan yang telah dilakukan, penulis menyadari masih banyak terjadi kesalahan. Untuk pengembangan kedepannya, penulis mengharapkan untuk dapat memperbaiki kesalahan-kesalahan tersebut. Dan agar perancangan kran air otomatis pada tempat berwudhu menggunakan sensor ultrasonik berbasis arduino uno ini dapat bekerja dengan baik, diharapkan menggunakan tandon air yang lebih besar lagi atau menggunakan saluran air pam.

\section{DAFTAR PUSTAKA}

[1] Adistya, Irman Supriadi. Pengembangan Sistem Monitoring Vibrasi pada Kipas Pendingin Menggunakan Accelerometer ADXL345 dengan Metode FFT Berbasis Labview. 2014. http://repository.uinjkt.ac.id/dspace/bitst ream/123456789/28276/1/IRMAN\%20S UPRIADI\%20ADISTYA-FST.pdf. $\quad\{25$ Juni 2018\}.

[2] Afdali, Muhammad. Perancangan Alat Ukur Digital untuk Tinggi dan Berat Badan dengan Output Suara berbasis Arduino UNO. 2017. https://www.researchgate.net/publicatio n/319475333_Perancangan_Alat_Ukur_ Digital_untuk_Tinggi_dan_Berat_Bada
n_dengan_Output_Suara_berbasis_Ard uino_UNO. $\{09$ Juli 2018\}.

[3] Anonim. Pengertian Relay dan Fungsinya. 20 September 2016, https//www.teknikelektronika.com/penge rtian-relay-fungsi-relay. $\{15$ Maret $2018\}$.

[4] Anonim. Prinsip Kerja Selenoid Valve. 21 Februari 2015

http://www.insinyoer.com/prinsip-kerjasolenoid-valve. $\{25$ Maret 2018\}.

[5] Arifin, Ilfan. Automatic Water Level Control Berbasis Mikrocontroller dengan Sensor Ultrasonik. 2015. http://www.lib.unnes.ac.id/20929/1/5301 411072-S.pdf. $\{20$ Maret 2018\}

[6] Astaril, Sutris. Kran Air Wudhu Otomatis Berbasis Arduino Atmega 328. 2013.http://jurnal.umrah.ac.id/wpcontent/uploads/2013/07/Sutris-Astari080120201029.pdf. \{15-05-2018\}.

[7] Hendrawan, Soebhakti, Paralax Ultrasonik Range Finder, 2009, https://hendrawan.files.wordpress.com/2 009/02/ping-paralax application.pdf \{08 Juli 2018\}.

[8] Herananda, Alfian Lantoni. Prototype Alat Bantu Parkir Mobil Berbasis Sensor Ultrasonik Ping Dan Mikrokontroler Arduino Uno. 2016. http://digilib.uinsuka.ac.id/23686/2/1162 0004pdf. \{10-05-2018\}.

[9] Kho, Dickson. Prinsip Kerja DC Power Supply. 2017.

http://teknikelektronika.com/prinsipkerja-dc-power-supply-adaptor/. $\quad\{08$ Juli 2018\}.

[10] Syahwil, Muhammad. 2017. Panduan Mudah Belajar Arduino Menggunakan Simulasi Proteus. Yogyakarta: Andi.

[11] Wibowo, Febry Hario. Prototype Smart Bathroom Berbasis Arduino Uno. 